\title{
ELECTRON INDUCED EMISSION OF NITROUS OXIDE IN THE UV-VIS SPECTRAL RANGE
}

\author{
J. OrszÁGH*, M. DANKo, Š. MATEJČÍK \\ Faculty of Mathematics, Physics and Informatics, Comenius University in Bratislava, Mlynská dolina, 84248 \\ Bratislava, Slovakia \\ * juraj.orszagh@uniba.sk
}

\begin{abstract}
The electron impact excitation of $\mathrm{N}_{2} \mathrm{O}$ was studied using the crossed electron-molecular beams method. Optical emission spectrum initiated by $50 \mathrm{eV}$ electron impact was recorded within the range 200-700 nm. Main emission bands arise from excited ion state $\mathrm{N}_{2} \mathrm{O}^{+}\left(\mathrm{A}^{2} \Sigma\right)$ and dissociative excitation into $\mathrm{N}_{2}{ }^{+}\left(\mathrm{B}^{2} \Sigma_{u}^{+}\right)$. The rotationally un-resolved excitation-emission cross sections for selected ion transitions were scaled to absolute values and their dependence on electron energy was determined. Several of them were determined for the first time.
\end{abstract}

Keywords: nitrous oxide, emission, spectrum, electron, excitation, fluorescence.

\section{Introduction}

Nitrous oxide has been the aim of studies for many years for wide variety of reasons. Its role in the chemistry of the upper atmosphere is considered to be significant due to its contribution to ozone decomposition $[1,2]$. The atmospheric chemistry is also a field where spectroscopic data and cross sections are critical. It is important in the field of astrophysics [3] as well as used in many technological applications such as $\mathrm{N}_{2} \mathrm{O}$ lasers $[4,5]$. Dissociation of nitrous oxide leads to production of various metastable fragments making it interesting for plasma and electrical discharges applications $[6,7]$.

The excitation of nitrous oxide by electron impact leads to various products. The most prominent one is $\mathrm{N}_{2} \mathrm{O}^{+}\left(\mathrm{A}^{2} \Sigma\right)$. Other excited products created via dissociative exitation are significantly less prominent [8]. In the UV-VIS spectral region it is possible to detect $\mathrm{NO}\left(\mathrm{B}^{2} \Pi\right)$ but its emission cross section at $100 \mathrm{eV}$ is approximately 20 times smaller than the emission cross section of $\mathrm{N}_{2} \mathrm{O}^{+}$bands [8]. The initial excitation of the $\mathrm{N}_{2} \mathrm{O}$ molecule is an optically allowed transition leading to repulsive state of $\mathrm{N}_{2} \mathrm{O}$ [9]. Van Sprang [9] also reported presence of $\mathrm{N}_{2}{ }^{+}$with its typical $391.4 \mathrm{~nm}$ spectral band at $100 \mathrm{eV}$. Other products of dissociative excitation emit light mostly in the IR region such as O I multiplets at $777.4 \mathrm{~nm}$ and $844.7 \mathrm{~nm}$ and N I multiplets at $821.1 \mathrm{~nm}$ and $869.1 \mathrm{~nm}$ or in the VUV region which are outside of the spectral area of this study.

Spectroscopic studies aimed at electron impact in gas phase were done in the past focusing on excitation cross sections $[9,10]$ and were mostly done in the visible spectral region. The vacuum UV region was studied by Sroka and Zietz [11] and later Malone et al. who evaluated cross sections for the VUV transitions in the absolute scale [12]. Michelin et al. [13] theoretically evaluated the elastic and excitation cross sections for electron impact on nitrous oxide.
Kawahara et al. [14] used an electron energy loss experimental technique to evaluate excitation of the $\mathrm{C}$ and D electronic states in nitrous oxide. Even though the emission of nitrous oxide has been studied well, the published absolute values of cross sections are often published only as a scattered values for selected energies. In this work we report whole curves: energy dependent cross sections for the emission cross section of the vibrationally resolved transitions of $\mathrm{N}_{2} \mathrm{O}^{+}\left(\mathrm{A}^{2} \Sigma\right.$ $\left.-\mathrm{X}^{2} \Pi\right)$.

\section{Experiment}

The experimental apparatus used for this study was described in detail in [15-17]. A simple scheme of the device is shown in the figure 1 . The electron beam was generated by trochoidal electron monochromator with heated tungsten filament used as electron source [18]. The energetic resolution of the electron beam was approximately $300 \mathrm{meV}$ and the electron current measured by the faraday cup was $900 \mathrm{nA}$ and was within $5 \%$ of this value in the range from $4 \mathrm{eV}$ up to $100 \mathrm{eV}$. The electron beam is perpendicular to the molecular beam which is formed by an effusive capillary - the gas entering the capillary has the ambient temperature. The concentration of molecules in the beam was kept low enough to only allow binary electron-molecule collisions. This was tested by measurement of signal intensity dependance on gas pressure in the capillary. The measurements were done at pressures where this dependance is strictly linear. The background pressure measured in the vacuum chamber outside of the molecular beam was $10^{-2} \mathrm{~Pa}$. The optical system of mirrors and lenses guides the photons emitted during deexcitation out of the vacuum chamber and focuses the beam onto the entrance slit of the optical monochromator. A thermoelectrically cooled photomultiplier working in the photon counting regime serves as a detector with noise less than 3 counts per second. 


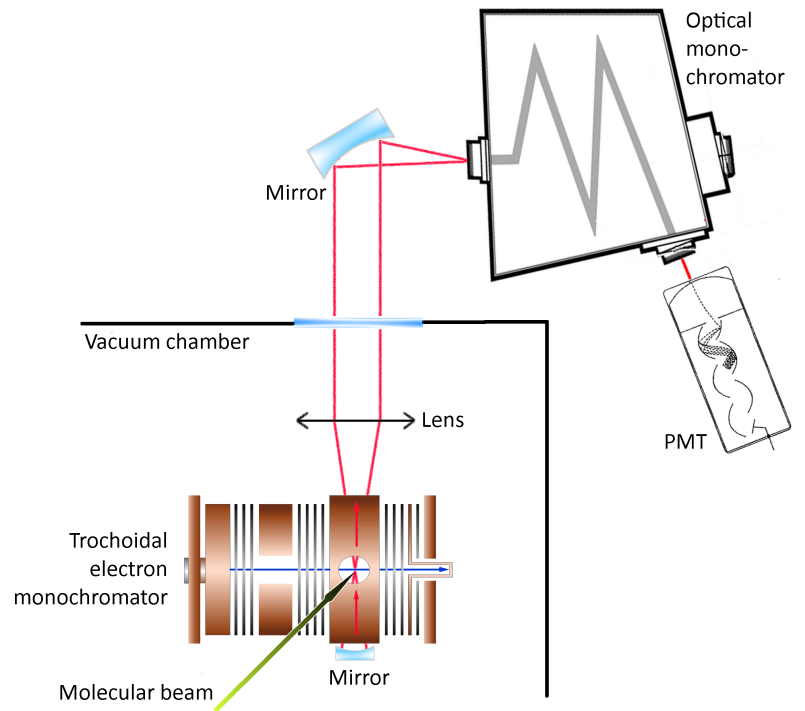

Figure 1. Simple scheme of the crossed beams experimental apparatus. Photon beam is shown in red, electron beam in blue and molecular bean in green. The photomultiplier (PMT) working in the photon counting regime is used as detector. The figure taken from [15] is updated to reflect some technical modifications.

The electron energy was calibrated by measurement of the emission cross section energy dependence of the $(0,0)$ band of $\mathrm{N}_{2}\left(\mathrm{C}^{3} \Pi_{u}-\mathrm{B}^{3} \Pi_{g}\right)$ at $337 \mathrm{~nm}$ and emission line of He I $\left(1 \mathrm{~s} 2 \mathrm{p}^{3} \mathrm{P}_{1,2}^{0}-1 \mathrm{~s} 4 \mathrm{~d}^{3} \mathrm{D}_{1,2,3}\right) 447.14 \mathrm{~nm}$ which are created by electron impact. The $\mathrm{N}_{2}\left(\mathrm{C}^{3} \Pi_{u}\right.$ - B $\left.{ }^{3} \Pi_{g}\right)(0,0)$ cross section exhibits a pronounced peak at $14.1 \mathrm{eV}$. The cross section for the HeI $\left(1 \mathrm{~s} 2 \mathrm{p}^{3} \mathrm{P}_{1,2}^{0}\right.$ $\left.1 \mathrm{~s} 4 \mathrm{~d}^{3} \mathrm{D}_{1,2,3}\right)$ transition exhibits a steep threshold at $23.736 \mathrm{eV}$. Optical resolution was experimentally determined by measurement of the Ar $294.3 \mathrm{~nm}$ line width, which was approximately $0.7 \mathrm{~nm}$ at $200 \mu \mathrm{m}$ width of entrance and output optical monochromator slits. Further increasing the optical resolution did not provide any significant improvement due to reduction of the signal-to-noise ratio.

\section{Emission spectrum}

The emission spectrum was measured at the incident electron energy of $50 \mathrm{eV}$ in the spectral range from $200 \mathrm{~nm}$ to $700 \mathrm{~nm}$. The Figure 2 represents overview spectrum with low resolution and high sensitivity in order to identify the emission bands. In this range most of the bands correspond to deexcitation of excited ion state $\mathrm{N}_{2} \mathrm{O}^{+}\left(\mathrm{A}^{2} \Sigma\right)$ to the electronic ground ion state $\left(\mathrm{X}^{2} \Pi\right)$. The wide bump between $550 \mathrm{~nm}$ and $700 \mathrm{~nm}$ is an artefact - background radiation of the tungsten filament serving as electron beam source that was able to reach the detector despite the shielding. According to van Sprang [9] there is NO $\left(B^{2} \Pi-X^{2} \Pi\right)$ system present at the wavelengths below $300 \mathrm{~nm}$. In our spectrum the signal intensity in this region was not high enough to distinguish possible photon signal from the noise. Also, according to [9] the $\mathrm{N}_{2}{ }^{+}$band at $391.4 \mathrm{~nm}$ was present in the spectrum measured at

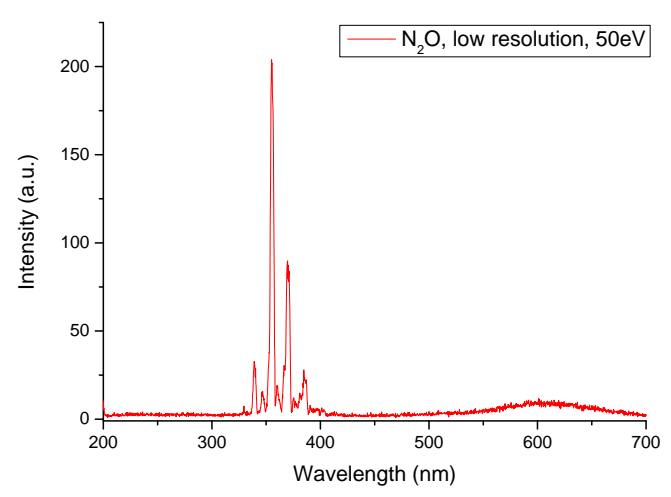

Figure 2. Overview emission spectrum of nitrous oxide induced by $50 \mathrm{eV}$ electrons impact corrected for apparatus spectral sensitivity.

$100 \mathrm{eV}$. In our spectrum measured at $50 \mathrm{eV}$ there is faint signal increase at this wavelength and its vicinity as well. This is in agreement with previous studies reporting the emission of dissociative excitation products of nitrous oxide to be significantly less prominent then $\mathrm{N}_{2} \mathrm{O}^{+}\left(\mathrm{A}^{2} \Sigma-\mathrm{X}^{2} \Pi\right)$.

We have recorded the spectrum of the nitrous oxide with increased resolution in the range from $330 \mathrm{~nm}$ to $410 \mathrm{~nm}$ (Figure 3). In the spectrum we were able to recognise individual peaks corresponding to various electron-vibronic transitions. These revealed two distinctive band heads for each transition which were identified according to the [19]. Due to limited resolving power of the spectrometer and low signal strength, we were not able to resolve the rotational transitions within the electron-vibronic bands. The spectrum is corrected for spectral sensitivity of the experimental apparatus. Since the nitrous oxide molecules have ambient temperature, the kinetic energy of the molecule after electron impact ionization and excitation does not change significantly and as the lifetime of the $\mathrm{N}_{2} \mathrm{O}^{+}\left(\mathrm{A}^{2} \Sigma\right)$ is approximately $230-260 \mathrm{~ns}$ [9] the produced ions at $300 \mathrm{~K}$ will travel approximately $0.1 \mathrm{~mm}$ before emission. That is well within the field of view limit of the used experimental device $(3 \mathrm{~mm})$ meaning that only negligible portion of the signal might be lost.

\section{Emission cross sections}

For the six most intensive electron-vibronic transitions of $\mathrm{N}_{2} \mathrm{O}^{+}\left(\mathrm{A}^{2} \Sigma-\mathrm{X}^{2} \Pi\right)$ the rotationally un-resolved emission cross sections as a function of electron energy were determined with $1 \mathrm{eV}$ electron energy step. The threshold of $\mathrm{N}_{2} \mathrm{O}^{+}\left(\mathrm{A}^{2} \Sigma-\mathrm{X}^{2} \Pi\right)(0,0,0) \rightarrow(0,0,0)$ corresponds to the value $16.4 \mathrm{eV}$ published by van Sprang [9]. The cross sections were recorded by measuring the spectral band intensity as a function of incident electron energy. The cross section curves are shown in the figures 4 and 5 . The emission cross section curves were calibrated to the absolute scale 


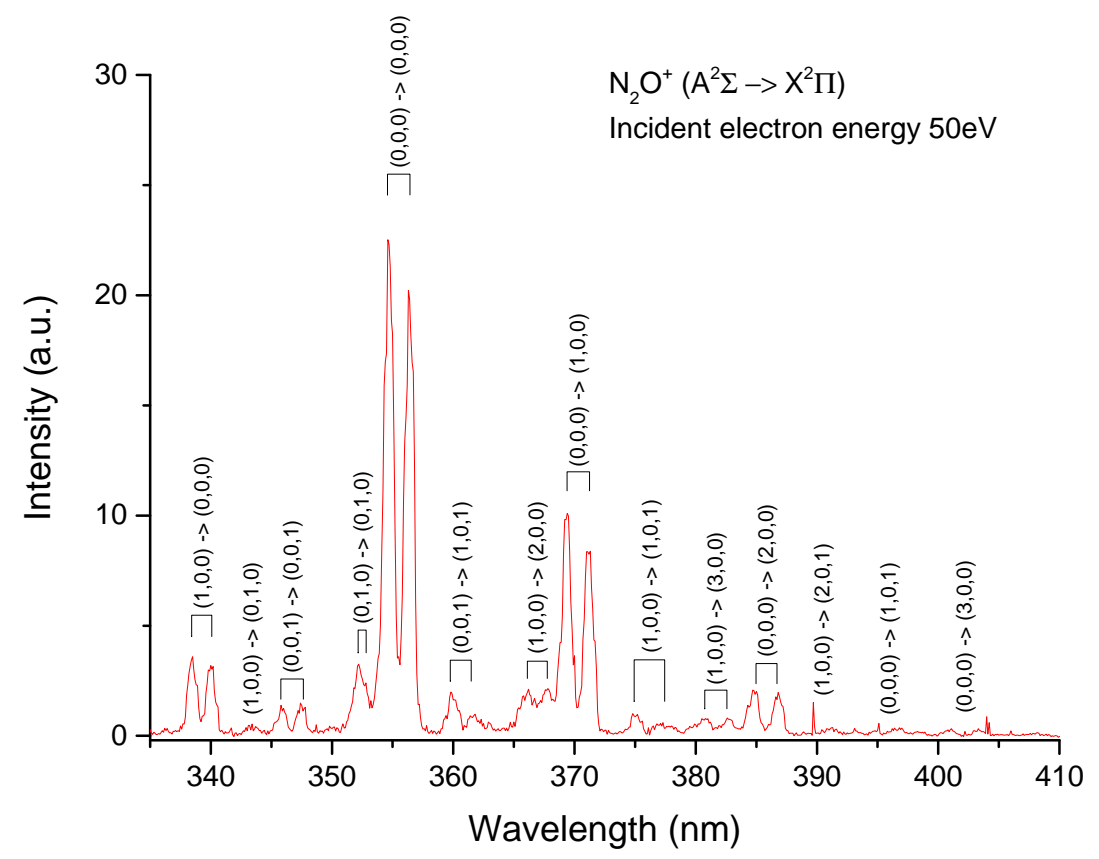

Figure 3. Part of the emission spectrum consisting of various electron-vibronic transitions of nitrous oxide ion.

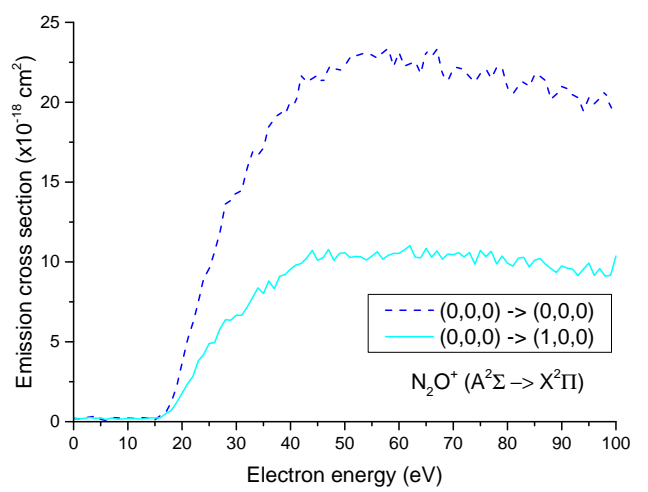

Figure 4. Emission cross sections in the absolute scale for the two most intensive vibronic $\mathrm{N}_{2} \mathrm{O}^{+}$transitions.

by normalizing the measured $(0,0,0) \rightarrow(0,0,0)$ relative curve to the cross section value published by van Sprang [9]. Then the spectrum intensity was adjusted to fit the value of the cross section at $50 \mathrm{eV}$ and all the other cross section curves were normalized according to the values of spectrum intensity at the corresponding wavelengths. The accuracy of such cross section curve determination method assumes that the shape of the molecular spectral band does not change with electron energy significantly. The uncertainty of the measured emission crossections is influenced by several factors.

The largest effect on the uncertainty in the cross sections is the spectral instensity calibration process. Our data are anchored to the mentioned cross section

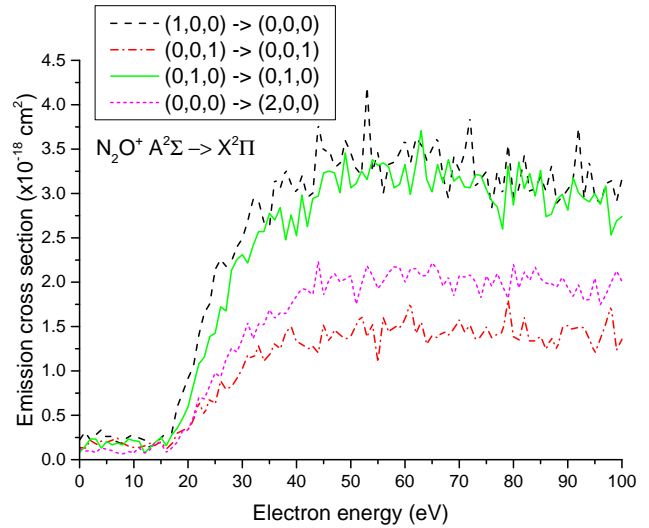

Figure 5. Emission cross sections in the absolute scale for other intensive vibronic $\mathrm{N}_{2} \mathrm{O}^{+}$transitions.

value published by van Sprang [9] who claims systematic uncertainty of $15 \%$. This uncertainty leads to a scaling factor affecting all data points. The uncertainty of the spectrometer is based mostly on detector sensitivity and it is between $20 \%$ for short wavelengths up to $250 \mathrm{~nm}$ and $5 \%$ for higher wavelengths. The variations of the electron beam current and molecular beam pressure were less than 5\%. Each cross section measurement was repeated several times and the stochastical error in intensity was approximately $5 \%$. Variations of these values affect the final cross section value linearly. From the figures 4 and 5 it can be seen that ratio between the vibronic levels is more or less constant especially within the upper half of the studied energy range. This is in agreement with [20] and $[9]$. 


\begin{tabular}{llll}
\hline \hline Transition & This work & {$[\mathbf{1 0}]$} & {$[\mathbf{9 ]}$} \\
$(0,0,0) \rightarrow(0,0,0)$ & 17.80 & 15.5 & 17.8 \\
$(0,0,0) \rightarrow(1,0,0)$ & 7.70 & 10.2 & 9.02 \\
$(1,0,0) \rightarrow(0,0,0)$ & 2.80 & 2.3 & 2.96 \\
$(0,0,1) \rightarrow(0,0,1)$ & 2.05 & - & 1.22 \\
$(0,1,0) \rightarrow(0,1,0)$ & 1.65 & - & - \\
$(0,0,0) \rightarrow(2,0,0)$ & 1.50 & 2.6 & 2.15 \\
\hline \hline
\end{tabular}

Table 1. Comparison of the cross section values at $100 \mathrm{eV}$ for various vibrational transitions of $\mathrm{N}_{2} \mathrm{O}^{+}\left(A^{2} \Sigma-X^{2} \Pi\right)$. The values are shown in $x 10^{-18} \mathrm{~cm}^{2}$.

In the table 1 the cross section values at $100 \mathrm{eV}$ electron energy are compared to previously published ones. The agreement between the determined values at $100 \mathrm{eV}$ is good for the first three transitions and slightly worse for the rest of them. That can be partially explained by lower intensity of these bands and worse signal-to-noise ratio. Generally present values are in good agreement with the earlier observations. The emission cross section for the transition $\mathrm{N}_{2} \mathrm{O}^{+}\left(\mathrm{A}^{2} \Sigma\right.$ - $\left.\mathrm{X}^{2} \Pi\right)(0,1,0) \rightarrow(0,1,0)$ was determined for the first time and most of the other cross sections were known only for several discreet energy values. In this work we managed to determine them in the energy range from threshold to $100 \mathrm{eV}$.

The data from the figures 4 and 5 are tabulated as supplement tables 2 and 3 at the end of the paper for easier further processing.

\section{Conclusions}

The emission spectrum of nitrous oxide induced by electron impact was studied by crossed beams method. The spectrum induced at $50 \mathrm{eV}$ consists of very intensive electron-vibronic transitions of $\mathrm{N}_{2} \mathrm{O}^{+}\left(\mathrm{A}^{2} \Sigma\right.$ $\left.\mathrm{X}^{2} \Pi\right)$ and weak $\mathrm{N}_{2}+\left(\mathrm{B}^{2} \Sigma_{u}^{+}\right)$band. Emission cross sections were determined as a function of electron impact energy in the range from threshold to $100 \mathrm{eV}$ for the six most intensive bands. The values at $100 \mathrm{eV}$ were compared to previously published values.

\section{Acknowledgements}

This project has received funding from the European Union's Horizon 2020 research and innovation programme under grant agreement No 692335. This work was supported by the Slovak Research and Development Agency APVV-15-0580 and the Slovak Grant Agency for Science (contract no. VEGA 1/0733/17).

\section{References}

[1] R. G. Prinn, P. G. Simmonds, R. A. Rasmussen, R. D. Rosen, F. N. Alyea, C. A. Cardelino, A. J. Crawford, D. M. Cunnold, P. J. Fraser, and J. E. Lovelock. The atmospheric lifetime experiment: 1. introduction, instrumentation, and overview. Journal of Geophysical Research: Oceans, 88(C13):8353-8367, 1983.

doi : 10.1029/JC088iC13p08353.
[2] R. P. Wayne. Chemistry of Atmospheres. Third edition. Oxford University Press, USA, 2006.

[3] L. M. Ziurys, A. J. Apponi, J. M. Hollis, and L. E. Snyder. Detection of interstellar $\mathrm{N}_{2} \mathrm{O}$ : A new molecule containing an N-O bond. Astrophysical Journal Letters, 436:L181, 1994. doi:10.1086/187662.

[4] M. Kitajima, Y. Sakamoto, R. J. Gulley, M. Hoshino, J. C. Gibson, H. Tanaka, and S. J. Buckman. Electron scattering from $\mathrm{N}_{2} \mathrm{O}$ : absolute elastic scattering and vibrational excitation. Journal of Physics B: Atomic, Molecular and Optical Physics, 33(9):1687-1702, 2000. doi: 10.1088/0953-4075/33/9/301.

[5] K. E. Fox and J. Reid. Dynamics of the $\mathrm{N}_{2} \mathrm{O}$ laser as measured with a tunable-diode laser. J. Opt. Soc. Am. B, 2(5):807-814, 1985. doi:10.1364/JOSAB.2.000807.

[6] G. Allcock and J. McConkey. Dissociation patterns in $\mathrm{N}_{2} \mathrm{O}$ following electron impact. Chemical Physics, 34(2):169 - 179, 1978. doi : 10.1016/0301-0104(78)80033-0.

[7] S. Barnett, N. Mason, and W. Newell. Production of the $\mathrm{N}_{2}\left(\mathrm{~A}^{3} \Sigma_{u}^{+}\right)$metastable state by electron impact dissociative excitation of $\mathrm{N}_{2} \mathrm{O}$. Chemical Physics, 153(1):283 - 295, 1991.

doi : 10.1016/0301-0104(91) 90024-N.

[8] J. W. McConkey, C. P. Malone, P. V. Johnson, C. Winstead, V. McKoy, and I. Kanik. Electron impact dissociation of oxygen-containing molecules - a critical review. Physics Reports, 466:1 - 103, 2008. doi:10.1016/j.physrep.2008.05.001.

[9] H. van Sprang, G. Mōhlmann, and F. J. de Heer. Emission of radiation due to ionization and dissociation of $\mathrm{N}_{2} \mathrm{O}$ by electron impact. Chemical Physics, 33(1):65 72, 1978. doi:10.1016/0301-0104(78)87071-2.

[10] I. D. Latimer and J. W. McConkey. Absolute cross sections for simultaneous ionization and excitation of $\mathrm{N}_{2} \mathrm{O}$ by electron impact. Proceedings of the Physical Society, 86(4):745-751, 1965. doi:10.1088/0370-1328/86/4/309.

[11] W. Sroka and R. Zietz. Dissociative excitation and ionization excitation in $\mathrm{N}_{2} \mathrm{O}$ with synchrotron radiation. Zeitschrift fur Naturforschung - Section A Journal of Physical Sciences, 28(5):794-796, 1973.

doi : 10.1515/zna-1973-0544.

[12] C. P. Malone, P. V. Johnson, J. W. McConkey, J. M. Ajello, and I. Kanik. Dissociative excitation of $\mathrm{N}_{2} \mathrm{O}$ by electron impact. Journal of Physics B: Atomic, Molecular and Optical Physics, 41(9):095201, 2008. doi : 10.1088/0953-4075/41/9/095201.

[13] S. E. Michelin, T. Kroin, and M. T. Lee. Elastic and excitation cross sections for electron - nitrous oxide collisions. Journal of Physics B: Atomic, Molecular and Optical Physics, 29(18):4319-4319, 1996. doi : 10.1088/0953-4075/29/18/026.

[14] H. Kawahara, D. Suzuki, H. Kato, M. Hoshino, H. Tanaka, O. Ingólfsson, L. Campbell, and M. J. Brunger. Cross sections for electron impact excitation of the $\mathrm{C}^{1} \Pi$ and $\mathrm{D}^{1} \Sigma^{+}$electronic states in $\mathrm{N}_{2} \mathrm{O}$. The Journal of Chemical Physics, 131(11):114307, 2009. doi:10.1063/1.3230150. 
[15] M. Danko, J. Orszagh, M. Ďurian, J. Kočišek, M. Daxner, S. Zöttl, J. B. Maljković, J. Fedor, P. Scheier, S. Denifl, and Š. Matejčík. Electron impact excitation of methane: determination of appearance energies for dissociation products. Journal of Physics B: Atomic, Molecular and Optical Physics, 46(4):045203, 2013. doi:10.1088/0953-4075/46/4/045203.

[16] J. Országh, M. Danko, P. Čechvala, and Š. Matejčík. Dissociative excitation of acetylene induced by electron impact: Excitation-emission cross-sections. The Astrophysical Journal, 841(1):17, 2017. doi:10.3847/1538-4357/aa6e54.

[17] D. Bodewits, J. Országh, J. Noonan, M. Durian, and S. Matejčík. Diagnostics of collisions between electrons and water molecules in near-ultraviolet and visible wavelengths. The Astrophysical Journal, 885(2):167, 2019. doi:10.3847/1538-4357/ab43c9.

[18] J. Matúška, D. Kubala, and Š. Matejčík. Numerical simulation of a trochoidal electron monochromator. Measurement Science and Technology, 20(1):015901, 2008. doi:10.1088/0957-0233/20/1/015901.

[19] J. H. Callomon, F. Creutzberg, and D. P. Craig. The electronic emission spectrum of ionized nitrous oxide, $\mathrm{N}_{2} \mathrm{O}^{+}: \mathrm{A}^{2} \Sigma-\mathrm{X}^{2} \Pi$. Philosophical Transactions of the Royal Society of London. Series A, Mathematical and Physical Sciences, 277(1266):157-189, 1974. doi:10.1098/rsta.1974.0048.

[20] I. Tokue, M. Kobayashi, and Y. Ito. Vibrational distributions of $\mathrm{N}_{2} \mathrm{O}^{+}\left(\mathrm{A}^{2} \Sigma\right)$ produced by electron impact on jet-cooled $\mathrm{N}_{2} \mathrm{O}$. Journal of Chemical Physics, 96:7458-7464, 1992. doi:10.1063/1.462396. 


\begin{tabular}{|c|c|c|c|c|c|c|}
\hline $\begin{array}{l}\text { Electron energy } \\
(\mathrm{eV})\end{array}$ & $\begin{array}{l}(0,0,0)- \\
-(0,0,0)\end{array}$ & $\begin{array}{l}(0,0,0)- \\
-(1,0,0)\end{array}$ & $\begin{array}{l}(1,0,0)- \\
-(0,0,0)\end{array}$ & $\begin{array}{l}(0,0,1)- \\
-(0,0,1)\end{array}$ & $\begin{array}{l}(0,1,0)- \\
-(0,1,0)\end{array}$ & $\begin{array}{l}(0,0,0)- \\
-(2,0,0)\end{array}$ \\
\hline 1 & 0.175 & 0.171 & 0.314 & 0.149 & 0.096 & 0.121 \\
\hline 2 & 0.305 & 0.211 & 0.221 & 0.233 & 0.102 & 0.218 \\
\hline 3 & 0.251 & 0.261 & 0.279 & 0.233 & 0.080 & 0.162 \\
\hline 4 & 0.371 & 0.211 & 0.337 & 0.130 & 0.134 & 0.210 \\
\hline 5 & 0.142 & 0.241 & 0.244 & 0.205 & 0.118 & 0.194 \\
\hline 6 & 0.076 & 0.130 & 0.268 & 0.168 & 0.102 & 0.218 \\
\hline 7 & 0.305 & 0.231 & 0.186 & 0.186 & 0.075 & 0.242 \\
\hline 8 & 0.175 & 0.161 & 0.175 & 0.168 & 0.064 & 0.170 \\
\hline 9 & 0.284 & 0.171 & 0.279 & 0.233 & 0.091 & 0.154 \\
\hline 10 & 0.229 & 0.201 & 0.256 & 0.214 & 0.080 & 0.137 \\
\hline 11 & 0.207 & 0.211 & 0.244 & 0.205 & 0.134 & 0.137 \\
\hline 12 & 0.218 & 0.171 & 0.221 & 0.075 & 0.069 & 0.154 \\
\hline 13 & 0.273 & 0.181 & 0.128 & 0.140 & 0.112 & 0.186 \\
\hline 14 & 0.207 & 0.241 & 0.186 & 0.196 & 0.203 & 0.154 \\
\hline 15 & 0.120 & 0.231 & 0.244 & 0.251 & 0.187 & 0.202 \\
\hline 16 & 0.382 & 0.241 & 0.303 & 0.158 & 0.080 & 0.121 \\
\hline 17 & 0.567 & 0.502 & 0.303 & 0.279 & 0.134 & 0.170 \\
\hline 18 & 1.211 & 0.693 & 0.594 & 0.354 & 0.198 & 0.299 \\
\hline 19 & 2.203 & 1.205 & 0.756 & 0.466 & 0.326 & 0.339 \\
\hline 20 & 3.665 & 1.777 & 0.919 & 0.596 & 0.331 & 0.339 \\
\hline 21 & 5.115 & 2.359 & 1.047 & 0.838 & 0.481 & 0.436 \\
\hline 22 & 6.184 & 2.831 & 1.408 & 1.080 & 0.705 & 0.655 \\
\hline 23 & 7.482 & 3.804 & 1.652 & 1.155 & 0.684 & 0.501 \\
\hline 24 & 8.998 & 4.216 & 1.757 & 1.388 & 0.833 & 0.695 \\
\hline 25 & 9.533 & 4.888 & 2.141 & 1.425 & 0.978 & 0.622 \\
\hline 26 & 10.656 & 4.959 & 2.258 & 1.723 & 0.930 & 0.889 \\
\hline 27 & 11.867 & 5.822 & 2.176 & 1.677 & 1.127 & 0.792 \\
\hline 28 & 13.667 & 6.384 & 2.234 & 2.133 & 1.256 & 0.824 \\
\hline 29 & 13.852 & 6.354 & 2.397 & 2.254 & 1.213 & 0.913 \\
\hline 30 & 14.375 & 6.675 & 2.490 & 2.310 & 1.357 & 1.026 \\
\hline 31 & 14.441 & 6.655 & 2.688 & 2.217 & 1.544 & 1.180 \\
\hline 32 & 15.870 & 7.167 & 2.933 & 2.412 & 1.362 & 1.123 \\
\hline 33 & 16.895 & 7.769 & 2.921 & 2.571 & 1.533 & 1.285 \\
\hline 34 & 16.677 & 8.382 & 2.677 & 2.571 & 1.517 & 1.115 \\
\hline 35 & 17.135 & 8.020 & 2.618 & 2.776 & 1.688 & 1.172 \\
\hline 36 & 18.520 & 8.813 & 3.165 & 2.701 & 1.592 & 1.317 \\
\hline 37 & 18.902 & 8.321 & 3.061 & 2.841 & 1.656 & 1.245 \\
\hline 38 & 19.393 & 9.104 & 3.270 & 2.478 & 1.646 & 1.430 \\
\hline 39 & 19.229 & 9.215 & 3.107 & 2.757 & 1.752 & 1.503 \\
\hline 40 & 20.058 & 9.546 & 3.002 & 2.524 & 1.843 & 1.325 \\
\hline 41 & 19.949 & 9.807 & 3.200 & 2.981 & 1.929 & 1.309 \\
\hline 42 & 21.694 & 9.907 & 2.967 & 2.627 & 1.913 & 1.245 \\
\hline 43 & 21.247 & 10.249 & 2.979 & 2.943 & 1.854 & 1.277 \\
\hline 44 & 21.487 & 10.720 & 3.782 & 2.971 & 2.233 & 1.204 \\
\hline 45 & 21.683 & 10.108 & 3.468 & 3.232 & 1.854 & 1.527 \\
\hline 46 & 21.192 & 10.269 & 3.491 & 3.251 & 2.030 & 1.325 \\
\hline 47 & 22.185 & 10.781 & 3.305 & 3.232 & 2.100 & 1.463 \\
\hline 48 & 22.174 & 10.098 & 3.317 & 3.009 & 2.004 & 1.406 \\
\hline 49 & 21.934 & 10.530 & 3.596 & 3.456 & 2.036 & 1.358 \\
\hline 50 & 22.294 & 10.580 & 3.456 & 3.064 & 2.073 & 1.390 \\
\hline
\end{tabular}

Table 2. Emission cross section values as a function of energy for the measured electron-vibronic transitions of $\mathrm{N}_{2} \mathrm{O}^{+}\left(A^{2} \Sigma-X^{2} \Pi\right)$ in the range $1-50 \mathrm{eV}$. The values are shown in $x 10^{-18} \mathrm{~cm}^{2}$. 


\begin{tabular}{|c|c|c|c|c|c|c|}
\hline $\begin{array}{l}\text { Electron energy } \\
(\mathrm{eV})\end{array}$ & $\begin{array}{l}(0,0,0)- \\
-(0,0,0)\end{array}$ & $\begin{array}{l}(0,0,0)- \\
-(1,0,0)\end{array}$ & $\begin{array}{l}(1,0,0)- \\
-(0,0,0)\end{array}$ & $\begin{array}{l}(0,0,1)- \\
-(0,0,1)\end{array}$ & $\begin{array}{l}(0,1,0)- \\
-(0,1,0)\end{array}$ & $\begin{array}{l}(0,0,0)- \\
-(2,0,0)\end{array}$ \\
\hline 51 & 22.796 & 10.279 & 3.270 & 3.111 & 1.752 & 1.519 \\
\hline 52 & 22.883 & 10.349 & 3.212 & 3.251 & 1.977 & 1.632 \\
\hline 53 & 23.079 & 10.319 & 4.201 & 3.158 & 2.185 & 1.382 \\
\hline 54 & 22.970 & 10.118 & 3.247 & 3.381 & 2.078 & 1.535 \\
\hline 55 & 22.992 & 10.369 & 3.468 & 3.316 & 1.929 & 1.099 \\
\hline 56 & 22.752 & 10.640 & 3.002 & 3.344 & 2.009 & 1.600 \\
\hline 57 & 23.123 & 10.168 & 3.340 & 3.297 & 2.110 & 1.438 \\
\hline 58 & 23.363 & 10.409 & 3.352 & 3.064 & 2.175 & 1.511 \\
\hline 59 & 22.250 & 10.540 & 3.456 & 3.102 & 2.164 & 1.487 \\
\hline 60 & 23.112 & 10.540 & 3.608 & 3.325 & 1.998 & 1.576 \\
\hline 61 & 22.261 & 10.750 & 3.340 & 2.990 & 2.148 & 1.770 \\
\hline 62 & 22.403 & 11.021 & 3.619 & 3.325 & 2.153 & 1.422 \\
\hline 63 & 22.545 & 10.299 & 3.561 & 3.707 & 2.068 & 1.552 \\
\hline 64 & 21.792 & 10.259 & 3.375 & 3.158 & 2.078 & 1.301 \\
\hline 65 & 23.199 & 10.851 & 3.503 & 3.018 & 2.217 & 1.398 \\
\hline 66 & 22.861 & 10.299 & 3.631 & 3.325 & 2.142 & 1.374 \\
\hline 67 & 23.319 & 10.690 & 3.189 & 3.120 & 1.955 & 1.455 \\
\hline 68 & 21.738 & 10.168 & 2.944 & 3.381 & 2.057 & 1.406 \\
\hline 69 & 21.323 & 10.489 & 3.410 & 3.139 & 1.843 & 1.471 \\
\hline 70 & 22.087 & 10.459 & 3.258 & 3.195 & 2.073 & 1.576 \\
\hline 71 & 22.229 & 10.580 & 3.456 & 3.074 & 2.057 & 1.438 \\
\hline 72 & 21.978 & 10.319 & 3.864 & 3.064 & 2.084 & 1.519 \\
\hline 73 & 21.585 & 10.590 & 3.072 & 3.213 & 2.004 & 1.358 \\
\hline 74 & 21.247 & 9.857 & 3.165 & 3.204 & 1.822 & 1.382 \\
\hline 75 & 21.792 & 10.730 & 3.247 & 3.046 & 2.073 & 1.495 \\
\hline 76 & 22.098 & 10.329 & 2.839 & 2.915 & 1.955 & 1.374 \\
\hline 77 & 21.498 & 10.670 & 3.247 & 2.850 & 2.100 & 1.414 \\
\hline 78 & 22.163 & 9.877 & 2.991 & 2.599 & 1.955 & 1.430 \\
\hline 79 & 22.163 & 10.369 & 3.549 & 3.307 & 1.817 & 1.802 \\
\hline 80 & 20.898 & 9.927 & 2.956 & 2.869 & 2.201 & 1.382 \\
\hline 81 & 20.516 & 9.737 & 3.049 & 3.353 & 1.934 & 1.333 \\
\hline 82 & 21.018 & 10.239 & 3.433 & 3.055 & 2.116 & 1.600 \\
\hline 83 & 21.312 & 10.289 & 3.014 & 3.223 & 2.020 & 1.317 \\
\hline 84 & 20.963 & 9.686 & 3.061 & 2.971 & 2.169 & 1.342 \\
\hline 85 & 21.705 & 10.108 & 3.189 & 3.260 & 2.041 & 1.390 \\
\hline 86 & 21.629 & 10.218 & 3.026 & 2.738 & 1.988 & 1.245 \\
\hline 87 & 21.356 & 9.857 & 3.317 & 2.766 & 1.982 & 1.382 \\
\hline 88 & 20.211 & 9.596 & 2.886 & 2.934 & 1.945 & 1.236 \\
\hline 89 & 20.451 & 9.335 & 2.967 & 2.990 & 2.057 & 1.487 \\
\hline 90 & 21.018 & 9.757 & 3.037 & 2.813 & 1.939 & 1.511 \\
\hline 91 & 20.843 & 9.616 & 3.154 & 3.176 & 1.838 & 1.455 \\
\hline 92 & 20.462 & 9.546 & 3.736 & 3.009 & 1.971 & 1.495 \\
\hline 93 & 20.287 & 9.144 & 2.944 & 2.943 & 1.795 & 1.487 \\
\hline 94 & 19.458 & 9.546 & 3.363 & 2.906 & 1.806 & 1.358 \\
\hline 95 & 20.287 & 9.927 & 2.967 & 2.999 & 2.046 & 1.196 \\
\hline 96 & 19.905 & 9.154 & 2.874 & 2.878 & 1.747 & 1.358 \\
\hline 97 & 20.243 & 9.586 & 3.096 & 3.083 & 1.854 & 1.527 \\
\hline 98 & 20.691 & 9.114 & 3.165 & 2.533 & 1.998 & 1.738 \\
\hline 99 & 19.676 & 9.164 & 2.909 & 2.692 & 2.126 & 1.236 \\
\hline 100 & 19.480 & 10.369 & 3.165 & 2.738 & 2.009 & 1.358 \\
\hline
\end{tabular}

Table 3. Emission cross section values as a function of energy for the measured electron-vibronic transitions of $\mathrm{N}_{2} \mathrm{O}^{+}\left(A^{2} \Sigma-X^{2} \Pi\right)$ in the range $51-100 \mathrm{eV}$. The values are shown in $x 10^{-18} \mathrm{~cm}^{2}$. 